\title{
Oral Health Literacy a Vital Determinant of Oral Health
}

Mohammad Mehdi Naghibi Sistani*

Oral Health Research Center and Department of

Community Oral Health, Institute of Health, Babol

University of Medical Sciences, Iran

*Correspondling author: Mohammad Mehdi Naghibi

Sistani, Oral Health Research Center and Department of Community Oral Health, Institute of Health, Babol

University of Medical Sciences, Iran

Received: J anuary 28, 2018; Accepted: February 21, 2018; Published: March 19, 2018

\section{Letter to Editor}

Healthy living in $21^{\text {st }}$ century needs variety of abilities and competencies, essentially literacy skill [1]. Literacy represents a constellation of skills including reading, writing, listening, basic mathematical calculation (numeracy), and speech comprehension (communication). Integrating the multidimensional definition of literacy to the health context emerged the concept of health literacy [2]. Interest on health literacy has grown over the last two decades. Parker, et al. [3] determined basically health literacy as the ability to apply literacy skills to health-related issues such as prescriptions, appointment cards, and medicine labels.

Adapted from health literacy background, the most common definition of oral health literacy is "the degree to which individuals have the capacity to obtain, process, and understand basic oral health information and services needed to make appropriate health decisions" [4]. This definition attends to functional literacy related to oral health, encompassing act on oral health information, navigate the health care system, and active communication with oral health professionals. Oral health literacy skills are critical to decrease oral health disparities and promote oral health [5].

Current research, however, reveals the relation between oral health literacy and dental service utilization, oral health knowledge, and oral self-care behaviour [6,7]. Lower caregivers' oral health literacy was also associated with lower knowledge, poor oral health behaviour, and worse caregiver-reported oral health status among their pre-school-aged children $[8,9]$. It is argued that oral health literacy act as a vital determinant of oral health [10].

\section{References}

1. Kanj M, Mitic W. Health Literacy and Health Promotion: Definitions, Concepts and Examples in the Eastern Mediterranean Region, 2009.

2. Institute of Medicine, Health literacy: A prescription to end confusion Washington, DC: National Academies Press, 2004.

3. Parker RM, Baker DW, Williams MV, Nurss JR. The test of functional health literacy in adults: a new instrument for measuring patients' literacy skills. J Gen Intern Med. 1995; 10: 537-541.

4. US Department of Health and Human Services, Healthy people 2010: oral health toolkit. Washington, DC: U.S. Government Printing Office, 2000.

5. Horowitz AM, Kleinman DV. Oral health literacy: a pathway to reducing oral health disparities in Maryland. J Public Health Dent. 2012; 72: S26-30.

6. Parker EJ, Jamieson LM. Associations between indigenous Australian ora health literacy and self-reported oral health outcomes. BMC Oral Health. 2010; 10: 3.

7. Naghibi Sistani MM, Virtanen JI, Yazdani R, Murtomaa H. Association of oral health behavior and the use of dental services with oral health literacy among adults in Tehran, Iran. Eur J Dent. 2017; 11: 162-167. 